\title{
Evaluation of The Biocompatibility of a New Biomembrane
}

\author{
Fatima Mrue $^{\mathrm{a} *}$, Joaquim Coutinho Netto ${ }^{\mathrm{b}}$, Reginaldo Ceneviva ${ }^{\mathrm{a}}$, João José Lachat ${ }^{\mathrm{c}}$, \\ José Antônio Thomazini ${ }^{\mathrm{c}}$, Helder Tambelini ${ }^{\mathrm{d}}$ \\ ${ }^{a}$ University of São Paulo, Faculty of Medicine, Department of Surgery \\ ${ }^{\mathrm{b}}$ University of São Paulo, Faculty of Medicine, Department of Biochemistry \\ ${ }^{\mathrm{c} U n i v e r s i t y ~ o f ~ S a ̃ o ~ P a u l o, ~ F a c u l t y ~ o f ~ M e d i c i n e, ~ D e p a r t m e n t ~ o f ~ M o r p h o l o g y ~}$ \\ ${ }^{\mathrm{d}}$ University of São Paulo, General Bioteriun \\ Faculdade de Medicina de Ribeirão Preto - USP, Departamento de Bioquímica e \\ Imunologia, Av. Bandeirantes, 3900,14049-900 Ribeirão Preto - SP, Brazil
}

Received: August 18, 2003; Revised: January 18, 2004

\begin{abstract}
Biocompatibility has been considered one of the most important items to validate a biomaterial for its application in human organisms. The present work evaluates the biocompatibility of a new biomembrane using in vivo assay in different animal species. The experiments to evaluate the cellular reaction were carried out through the implantation of the material into the subcutaneous tissue of animals and the results showed a good reaction of the host tissue without any signal of fibrosis or rejection. The cell adhesion experiments were done by means of the measure of the DNA content on the material surface after its implantation into the subcutaneous tissue of animals and the results showed a growing number of DNA that was proportional to the time of implantation. The healing process was evaluated using a dermal ulcer model and the results showed a good tissue repair resembling a physiologic process. The overall results presented here lead to the conclusion that this new biomembrane is a biocompatible material but more research must be done, as it is a new material desired for medical use.
\end{abstract}

Keywords: Biomaterial, biomembrane, biocompatibility

\section{Introduction}

To manage a variety of challenging clinical situations caused by the loss, injury or disease of important or vital organs and tissues such as bone, soft tissue, heart, trachea, blood vessels, dermal ulcers, etc., researchers have long been engaged in seeking an ideal material capable of meeting the essential criteria of biocompatibility, innocuity, easy handling, and affordability for the people who need it. Several materials have been developed for these purposes, including silicon, polypropylene, hydroxyapatite and others. Because biocompatibility is one of the most important requirements for these materials, in-depth studies are required of their characteristics and of their interaction with the humans in which they are expected to work.

Biocompatibility can be evaluated by "in vivo" and "in vitro" assays. Several evaluative methods have been described, such as cellular reaction ${ }^{1}$, cell adhesion ${ }^{2}$ and the healing process ${ }^{3}$.

In this article, we present a new biomembrane designed

*e-mail: fatimamrue@ig.com.br for medical applications in tissue repair, evaluating it from the standpoint of its biocompatibility.

\section{Materials and Methods}

\section{The biomembrane}

The new biomembrane presented here is made of natural latex extracted from the rubber tree Hevea brasiliensis and manufactured by a process that differs from the conventional technique used in the rubber industry for manufacturing gloves, drains, tires, urinary or tracheal tubes and other devices.

\section{Manufacturing process}

The process, which is very simple, is briefly described below.

Natural latex is collected from the rubber tree, using ammonia as the only preservative. The latex thus collected 
is centrifuged to reduce its protein content, particularly the allergenic proteins. A sulfur composition is then added as the only curing agent, after which the latex is polymerized at low temperatures in a glass mold, a procedure that results in a biomembrane. Finally, the product is sterilized by the ethylene oxide method.

\section{Biocompatibility tests}

\section{Cellular reaction}

The cellular reaction was studied through subcutaneous implants of $0.5 \times 0.5 \mathrm{~cm}$ fragments of the biomembrane in the ventral wall of mongrel dogs. The implantation sites were at least 2.0 $\mathrm{cm}$ apart. The experiment involved $6 \mathrm{dogs}$, each of which received 8 implanted fragments. Two fragments, including the surrounding tissue, were removed weekly from each dog, from the $1 \stackrel{\text { st }}{ }$ to the $4^{\text {th }}$ week. The tissues thus removed were prepared for histological examination using hematoxylin-eosin and Masson's trichrome method. This study focused on the reactions to foreign bodies and on the presence of fibrotic tissue.

\section{Cell adhesion}

This experiment involved the implantation of fragments of the biomembrane in the subcutaneous tissue of dogs, as described above, and in the peritoneal cavity of rats. The fragments were subsequently removed for quantitative analyses and morphological studies.

\section{Quantitative analysis}

The implanted fragments were removed according to the following schedule: 0, 2, 6, 12 and $24 \mathrm{~h}$ after implantation. They were then subjected to a DNA analysis, as described by Labarca and Paigen ${ }^{4}$.

\section{Morphological analysis}

The morphological features of the adhered cells were examined by scanning electron microscopy 12 and $24 \mathrm{~h}$ after implantation.

\section{Healing process}

The healing process was studied using the dermal ulcer model in rabbit ear ${ }^{5}$. Four $0.5 \mathrm{~cm}$ ulcers were made to the depth of the cartilage in each rabbit ear, using a $0.5 \mathrm{~cm}$ circular dermatologic punch device. Two groups were set up. In one group, the ulcer was treated with a fragment of the biomembrane, while in the other group, which served as the control group, the ulcer was treated with ointment (Fibrase Aché). The healing process was evaluated after periods of 1 , 3, 7 and 14 days following surgery, comprising 6 events in each period. The treated ulcer was removed as described previously and prepared for histological study using hematoxylineosin and Masson's trichrome method. The study focused on the presence of new vessels, epithelialization and fibrosis.

\section{Results}

The biomembrane

The biomembrane obtained was thin, elastic and easy to handle. Its structure was composed of polyisoprene chains cross-linked with sulfur bridges and natural latex-related proteins and phospholipids (Fig. 1).

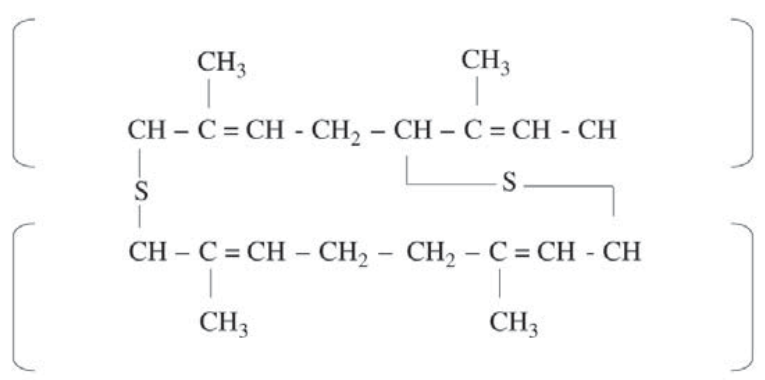

(a)

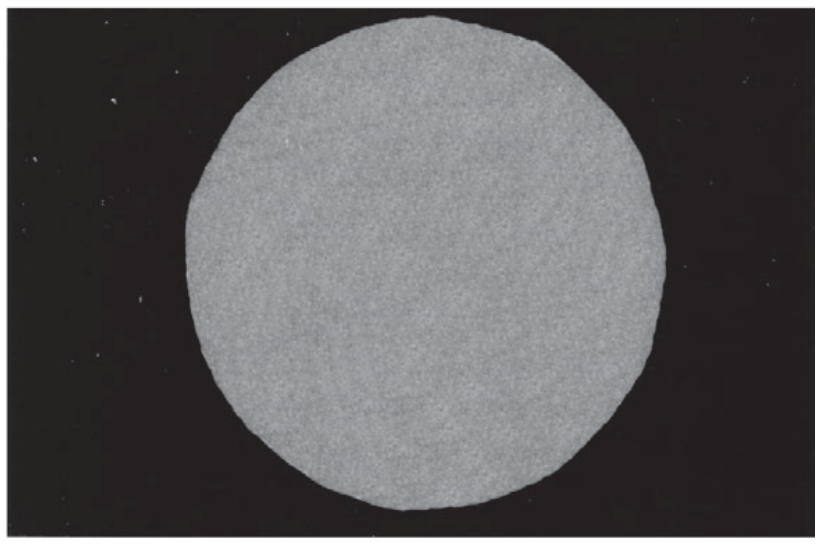

(b)

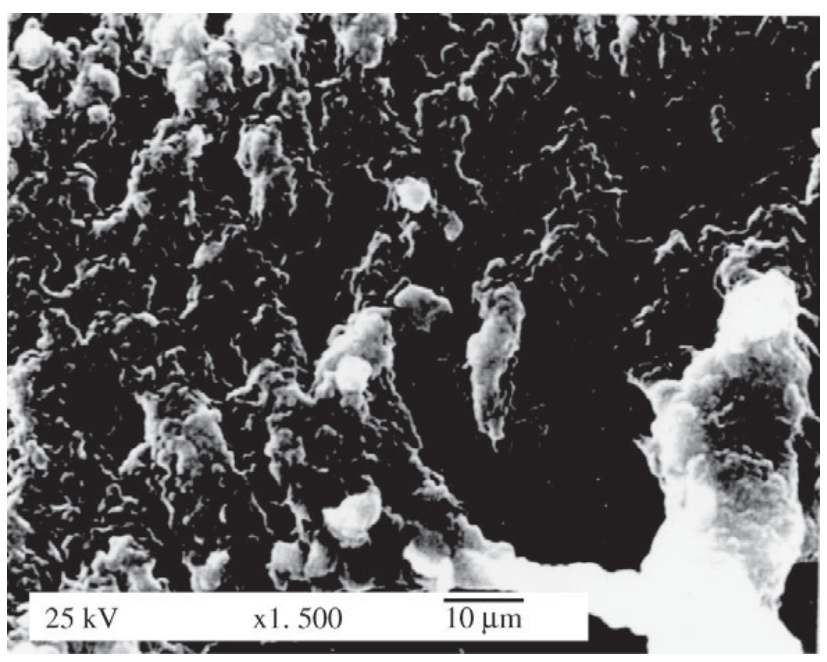

(c)

Figure 1. a) Basic chemical description; b) Macroscopic aspect; c) Microscopic aspect. 


\section{Cellular reaction}

Inflammatory cells

Moderate amounts of inflammatory cells were visible in the first week after implantation, gradually decreasing and disappearing completely by the fourth week (Fig. 2).

\section{Foreign body reaction}

Very minor amounts of Langherhans cells were observed even in the fourth week, comprising less than 5 cells per field with 40x magnification (Fig. 3).

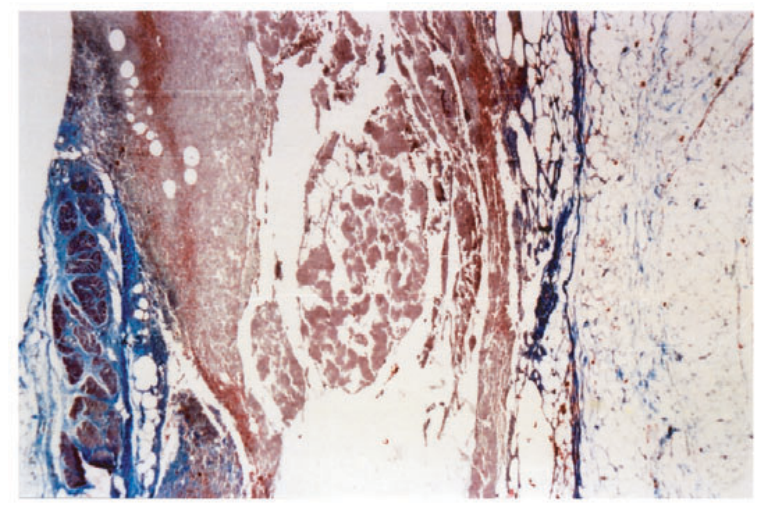

(a)
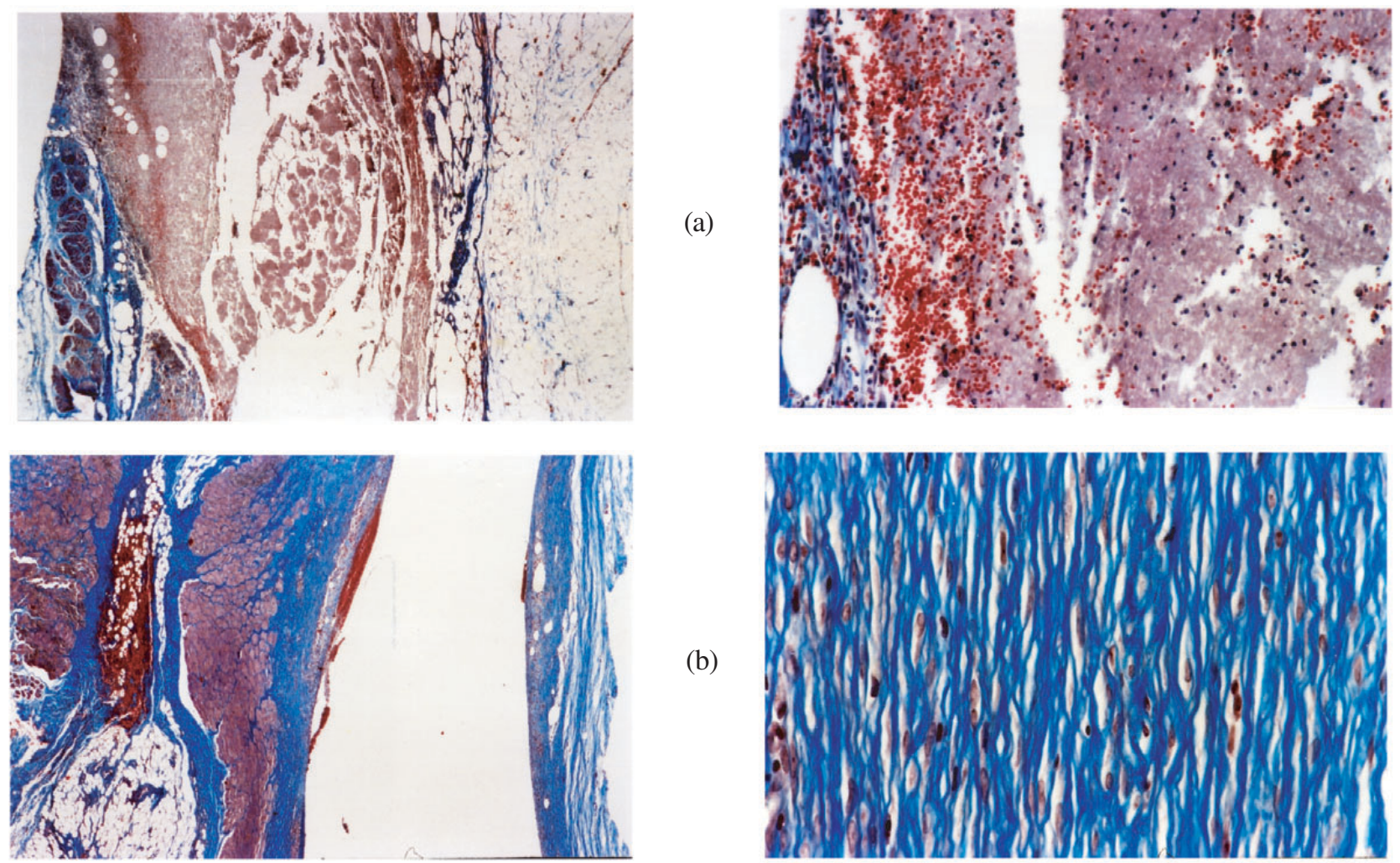

(b)

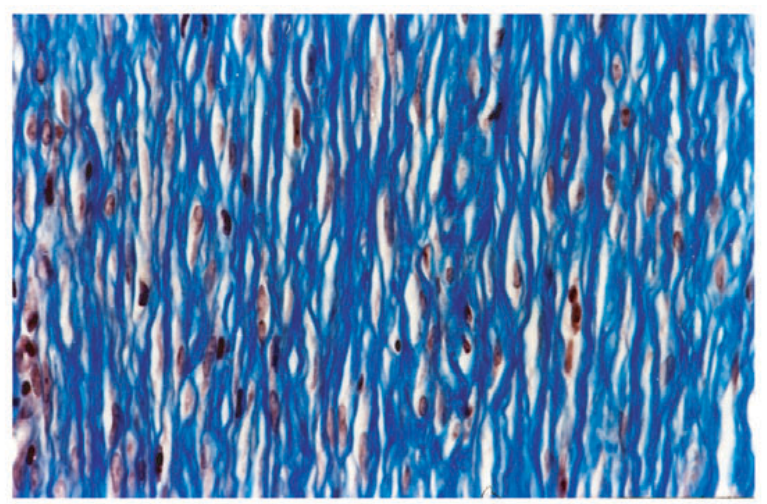

Figure 2. Tissue reaction: a) first week: Overview on the left; detailed view on the right. In these pictures the loccus of the implanted fragment can be seen, fulfilled with a amorphous substance and a moderate ammount of inflammatory cells; b) fourth week: Overview on the right; detailed view. These pictures show the the collagen fibers presented in an organized fashion.
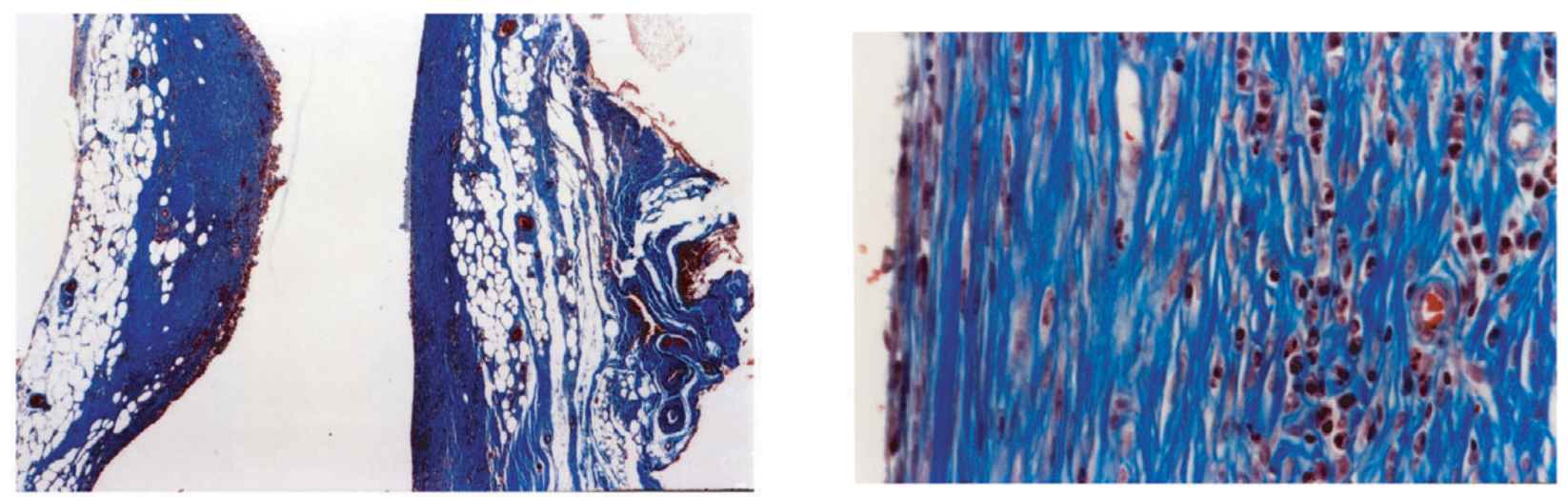

Figure 3. Tissue reaction - third week. Overview on the left; detailed view on the right in which the Langherhans cells and the collagen fibers can be seen. 


\section{Collagen fibers}

The presence of collagen fibers increased gradually and orderly, resembling a natural reaction. Excessive proliferation was not observed until the fourth week (Fig. 4).

Extrusion of the fragments did not occur in any implanted site and the locus of the implantation was preserved in all the periods studied (Fig. 1-4).

\section{Cell adhesion}

The number cells adhering to the fragments grew over time (Fig. 5).

With regard to the morphological features, the cells adhering to the material removed from the peritoneal cavity of rats and viewed under the scanning electron microscope appeared to be generally round in shape with a slightly rough surface. The cells in the subcutaneous tissue of dogs were approximately hexagonal in shape with a slightly rough surface (Fig. 6). In both the subcutaneous tissue and peritoneal cavity, the cells were visible on a network of an amorphous substance resembling a provisional matrix.

\section{The healing process}

\section{Injured area}

The injured área of the group that received implanted biomembrane fragments was filled out with organized tissue and new vessels, while in the control group the tissue was irregular with evident contraction of the edges (Fig.7).

\section{Epithelialization}

The group treated with the biomembrane displayed complete epithelialization of most ulcers by the $7^{\text {th }}$ day and of all the ulcers by the $14^{\text {th }}$ day. In contrast, complete epithelialization was only visible in any ulcer of the control group on the $14^{\text {th }}$ day (Fig.8).

\section{Collagen fibers}

The presence of organized collagen fibers was observed in the biomembrane group from day 1 to 14 , with no sign of fibrosis such as that clearly visible in the control group (Fig. 9).

\section{Angiogenesis}

The presence of new vessels indicating tissue repair was clearly noted from the first day on in the group implanted with biomembrane fragments, but was not evident in the control group (Fig. 10).

\section{Discussion}

The biomembrane presented here was developed fortuitously in 1994 and subjected to research at the Univer-

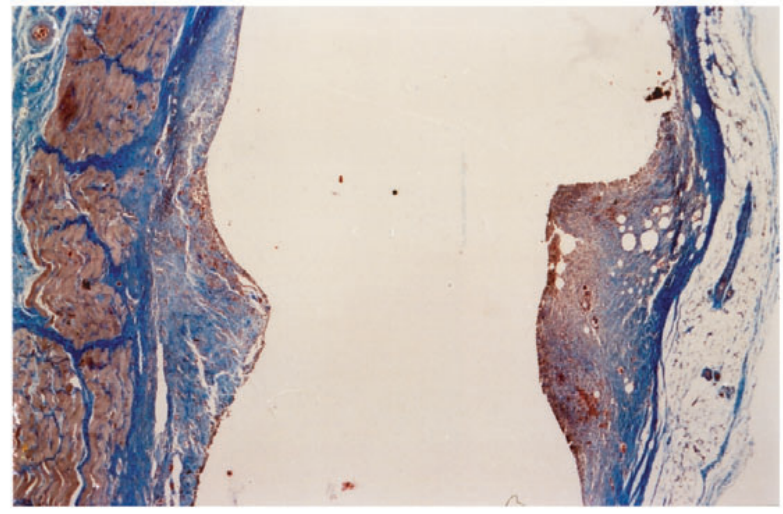

(a)

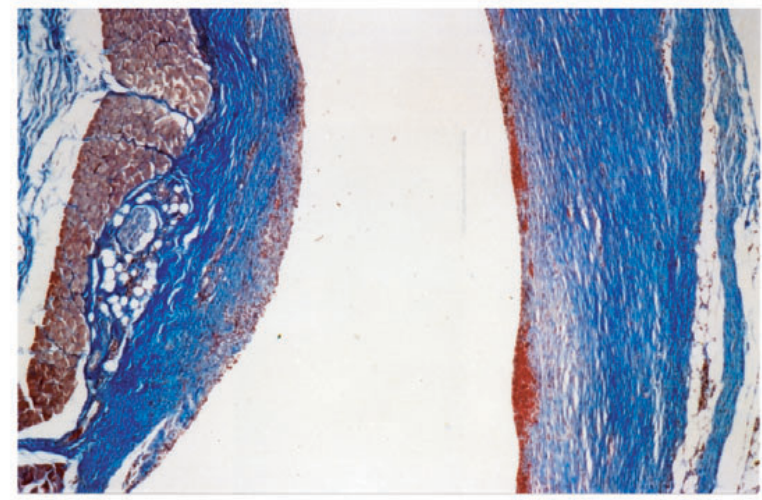

(b)

Figure 4. Tissue reaction - A - second week; B - fourth week. Collagen fibers can be seen in a very organized fashion since the second week.

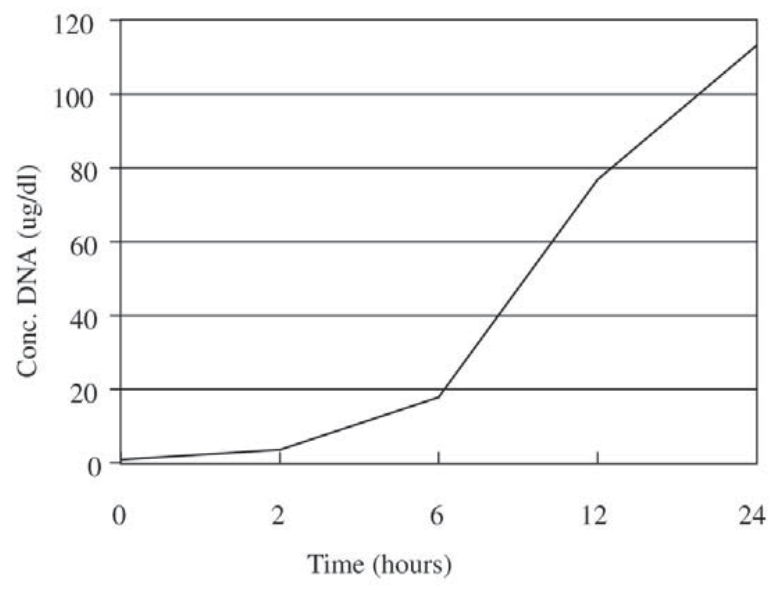

Figure 5. DNA concentration of cells adhered to the fragments of the biomembrane. 


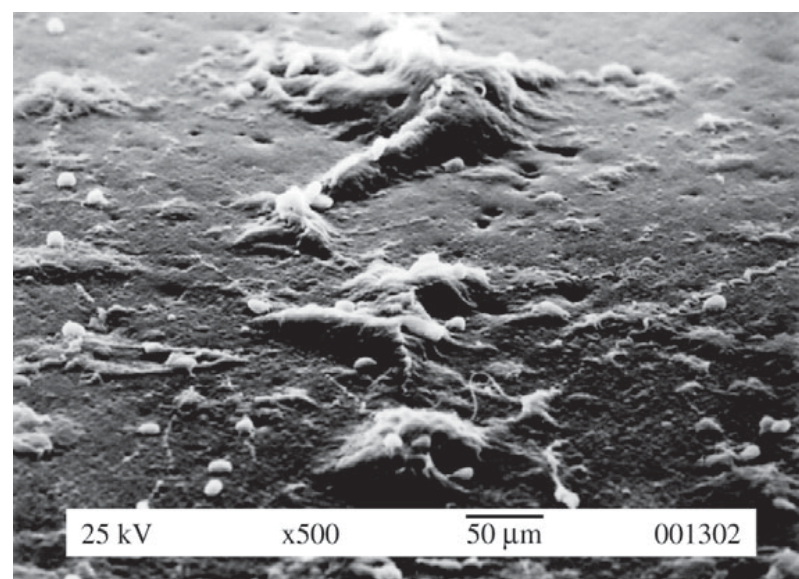

(a)

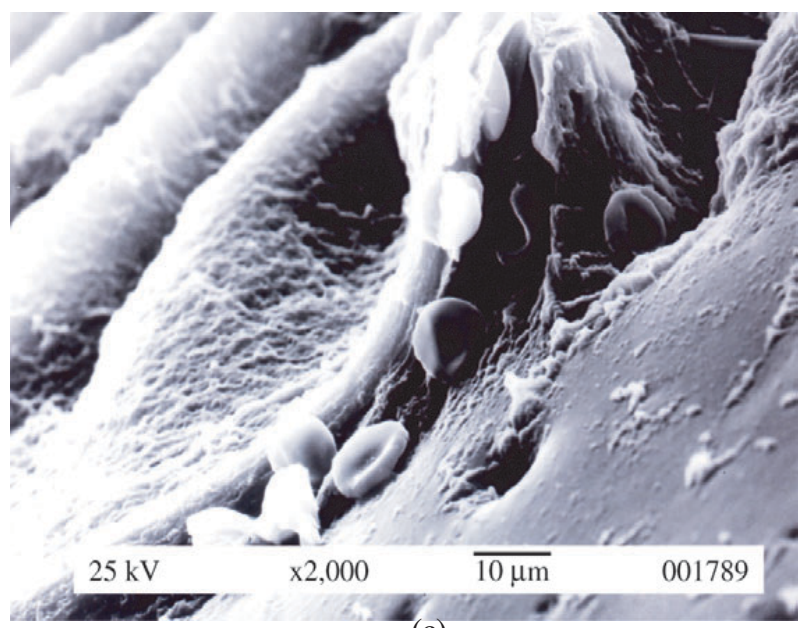

(c)

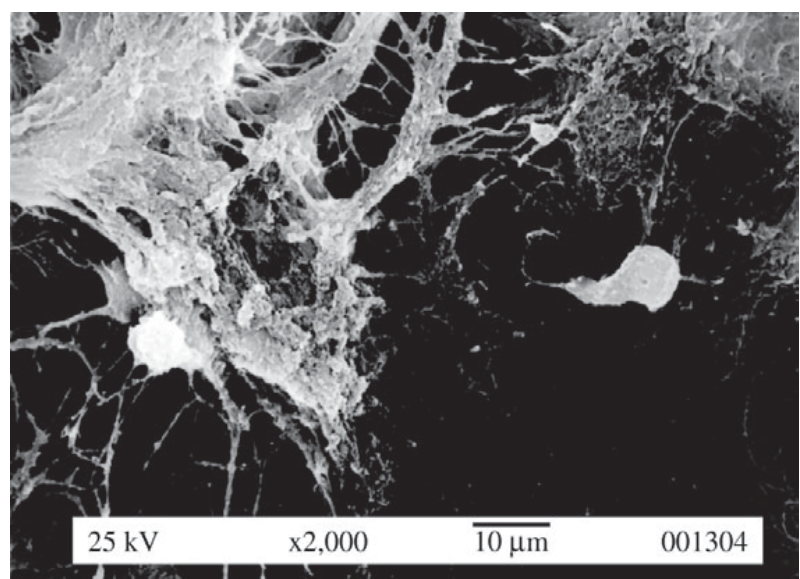

(b)

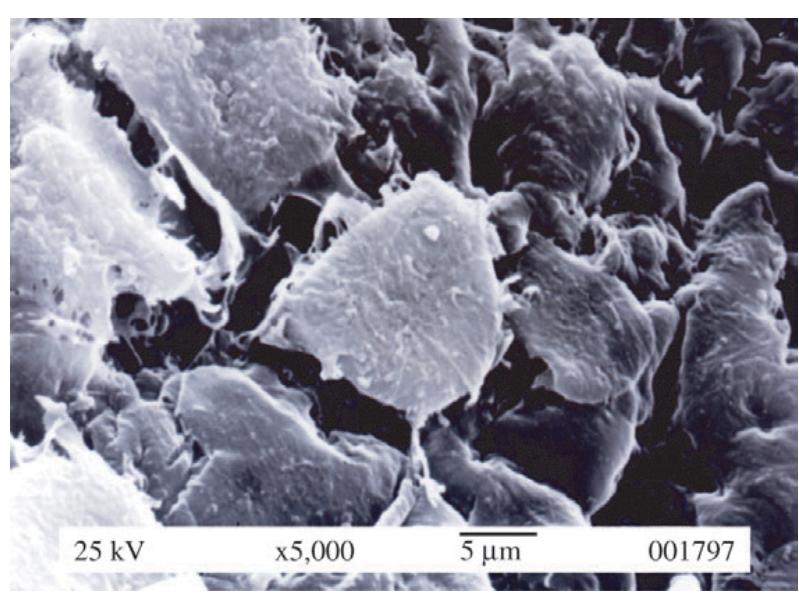

(d)

Figure 6. Electronic microscopy of cells and tissues $12 \mathrm{~h}$ after implantation of the biomembrane. a) and b) - removed from rats. In a) an amorphour substance covering the biomembrane was observed; b) detail of cells. c) and d) - removed from dogs. In c) an amorphous substance covering the biomembrane was observed with some red blood cells over it; e) detail of cells.

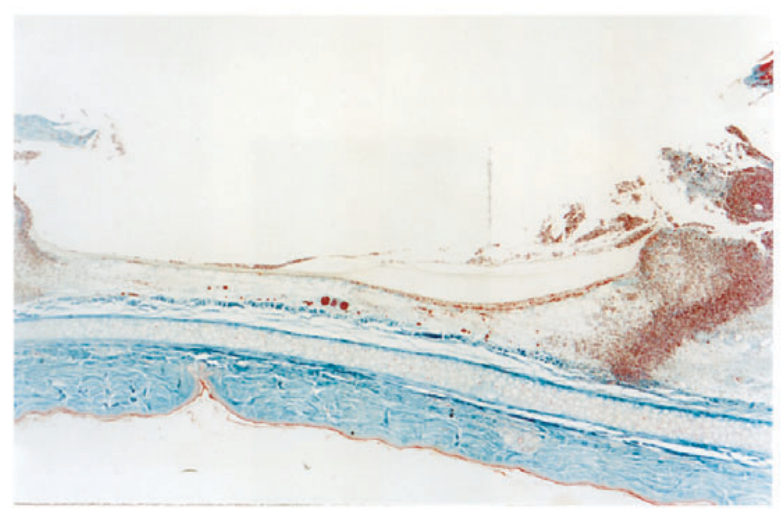

(a)

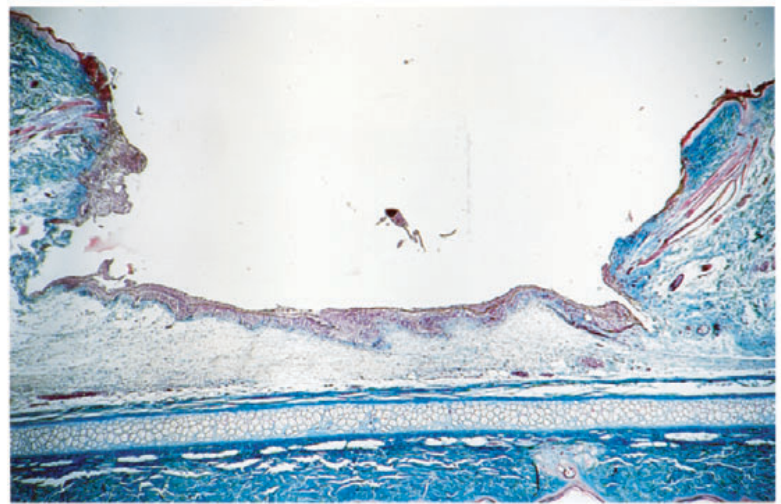

(b)

Figure 7. Healing process. First day: a) biomembrane group; b) control group. Note the evidence of new vessels and the absence of contraction of the edges in the biomembrane group. 


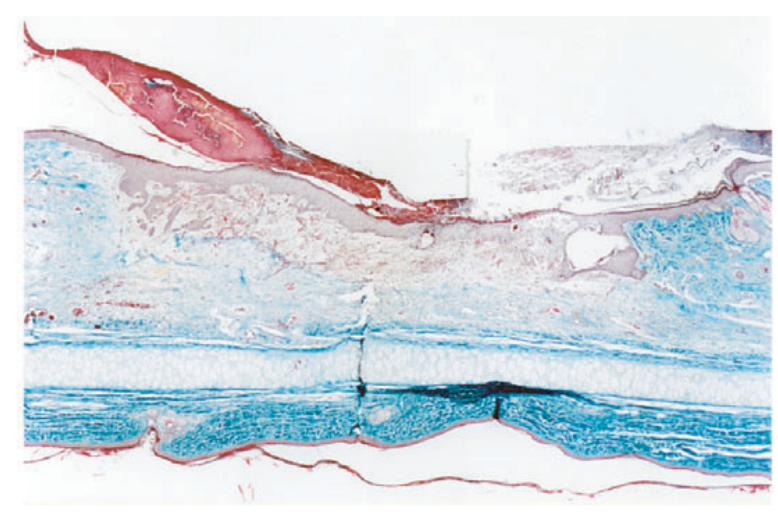

(a)

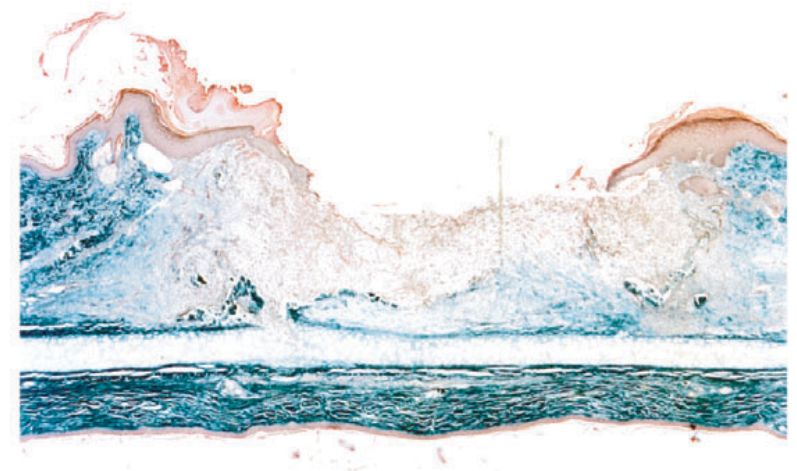

(b)

Figure 8. Healing process. Seventh day: a) biomembrane group; b) control group. Note the collagen fibers coming up and the epithelialization almost completed in the biomembrane group. Fibrotic tissue can be observed from the edges to the center in control group.

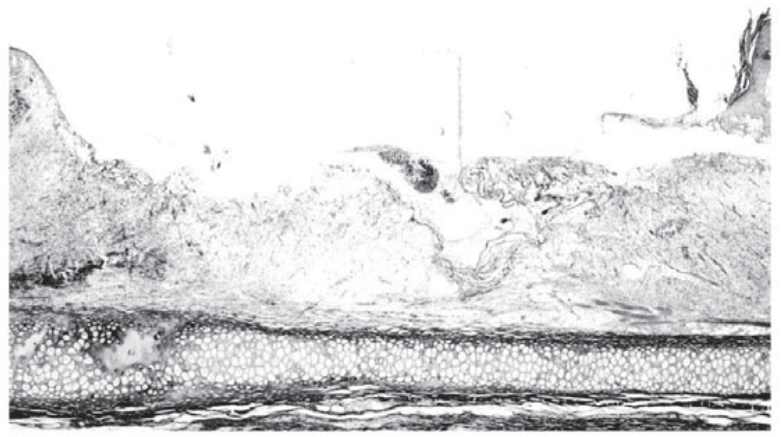

(a)

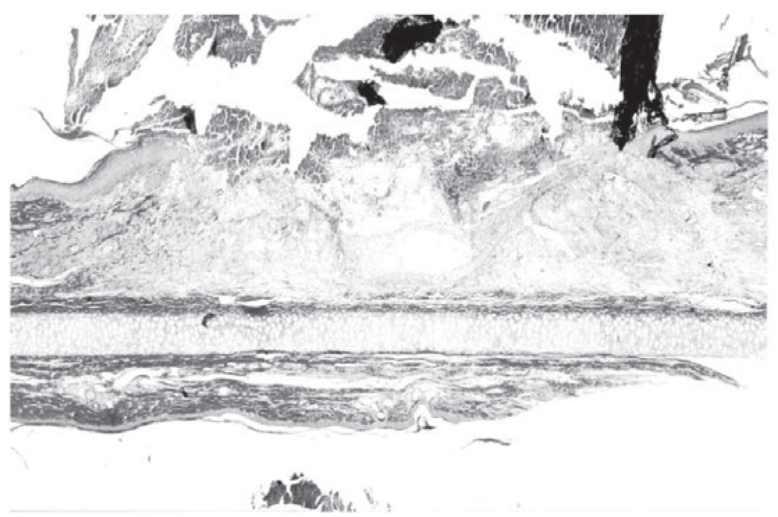

(b)

Figure 9. Healing process. Fifth day: a) biomembrane group; b) control group. The collagen fibers appear in an organized fashion and in the control group they appear in less amount than in the other group.

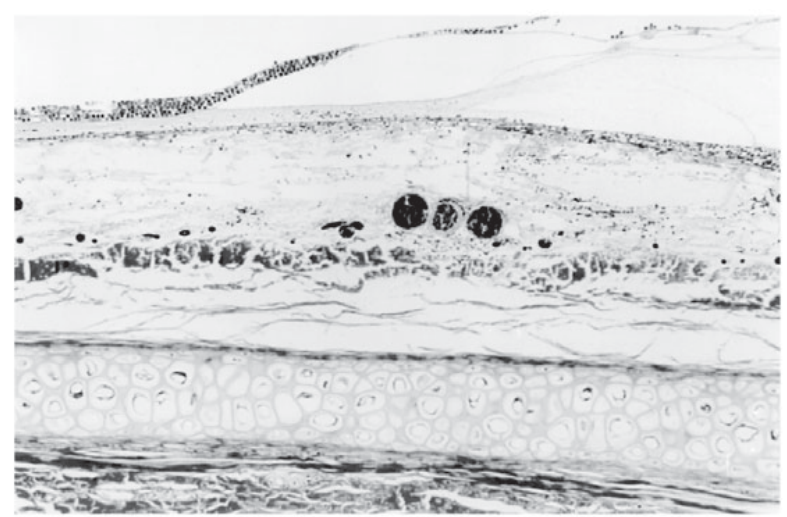

Figure 10. Angiogenesis. Detailed view of the picture $8 \mathrm{~A}$ in wich we can see many vessels. sity of São Paulo in Brazil and has been the subject of research since then. Several experimental researches in animals have been carried out at the University of São Paulo using this material to replace vessels, esophagus, pericardium and abdominal wall. In all of these studies, the biomembrane proved to promote rapid tissue repair. In several challenging situations, clinical studies were carried out under strict ethical guidelines. The application of this membrane in the treatment of a leg ulcer which healed with great difficulty ${ }^{6}$ produced an exciting result and contributed toward healing, providing greater comfort in dressing changes.

One of the most important factors in the evaluation of a material's biocompatibility is its ready acceptance by the host, eliciting an inflammatory response that should resemble that of the normal healing process. In this regard, 
"in vivo" implants are preferable, since they provide more realistic information than "in vitro" systems ${ }^{7}$ about the host's responses at the interface between the implanted material and the surrounding environment.

The biomembrane presented here proved to be suitable for cell adhesion, displaying a normal appearance under an electron microscope, showing no aberrant or abnormal images. The cellular reaction elicited by the material undoubtedly resembled that of normal tissue repair and not that of a rejection process. The biomembrane proved able to promote organized tissue repair in a rabbit ear dermal ulcer with no contraction wound or fibrotic tissue formation.

As regards the allergenicity and toxicity of latex products, it should be emphasized that the biomembrane presented here is a completely new material whose manufacturing process differs from the traditional one. This biomembrane contains no toxic product such as carbamate, which is conventionally used in the rubber industry, nor any other adjuvants or preservatives. The allergic reactions caused by latex proteins is already known and, as reported by Holmes ${ }^{8}$, this allergic reaction is expressed in previously sensitized individuals, generally taking several years to manifest itself. Latex allergic reaction is prevalent in women, in individuals with atopic eczema, with spina bifica and in individuals who underwent multiple genitourinary instrumentations during childhood 9 .

The experiments carried out with the biomembrane presented here demonstrated its biocompatibility, promoting a good healing process in injured rabbit ear.

We conclude that the natural latex biomembrane pre- sented here is a promising material for use in the field of medicine, specifically in tissue repair applications. Further studies are naturally required to better understand this new material and several researches are currently ongoing.

\section{References}

1. Abela-Formanek, C., Amon, M.; Schauersberger, J.; Schild, G.; Kolodjaschna, J.; Barisani-Asenbauer, T.; Kruger, A. J. Cataract Refract Surg, v. 28, n. 7, p. 116072, 2002.

2. Ohnishi, Y.; Yoshitomi, T.; Sakamoto, T.; Fujisawa, K.; Ishibashi, T. J. Cataract Refract Surg, v. 27, n 12, p. 203640, 2001.

3. Quester, R.; Klosterhalfen, B.; Stützer, H.; Schröder, R.; Klug, N. J. Neurosurg, v. 96, n 4, p. 760-9, 2002.

4. Labarca, C., Paigen, K. Ana Biochem, v. 102, p. 344$352,1980$.

5. Mustoe, T. A.; Pierce, G. F.; Morishima, C.; Deuel, T. F. J Clin Invest, v. 87, p. 694-703, 1991.

6. Frade, M. A.; Valverde, R. V.; Coutinh-Netto, J.; Foss, N. T. J Invest Dermatol, v. 4, p. 1-5, 2001.

7. Marchant, R.E.; Miler, K. M.; Anderson, J.M. J Biomed Mater Res, v.18, p.1169-1190, 1984.

8. Holmes, H. "Latex Prtotein Allergenicity. A Business Perspective", in Rubber Research Institute of Malasya. Latex Proteins and Glove Industry. Proc. Irtc 1993. Workshop On Latex Proteins, 1994.

9. Laxenaire, M. C.; Moneret - Vautrin , D. A. Chirurgie, v. 120, p. 526-532, 1994-95. 
